\title{
Diagnostic Performance of Des- $\gamma$-carboxy Prothrombin for Hepatocellular Carcinoma: A Meta-Analysis
}

\author{
Rong Zhu, ${ }^{1}$ Jing Yang, ${ }^{1}$ Ling Xu, ${ }^{2}$ Weiqi Dai, ${ }^{1}$ Fan Wang, ${ }^{1}$ Miao Shen,, Yan Zhang, \\ Huawei Zhang, ${ }^{1}$ Kan Chen, ${ }^{1}$ Ping Cheng, ${ }^{1}$ Chengfen Wang, ${ }^{1}$ Yuanyuan Zheng, ${ }^{1}$ Jingjing Li, ${ }^{1}$ \\ Jie Lu, ${ }^{1}$ Yingqun Zhou, ${ }^{1}$ Dong $\mathrm{Wu}^{3}$ and Chuanyong Guo ${ }^{1}$ \\ ${ }^{1}$ Department of Gastroenterology, Shanghai Tenth People's Hospital, Tongji University School of Medicine, Shanghai 200072, China \\ ${ }^{2}$ Department of Gastroenterology, Tongren Hospital, Shanghai Jiao Tong University School of Medicine, Shanghai 200050, China \\ ${ }^{3}$ Department of Gastroenterology, Ningbo No. 2 Hospital, Ningbo 315010, China
}

Correspondence should be addressed to Dong Wu; wudong65@163.com and Chuanyong Guo; guochuanyong@hotmail.com

Received 19 February 2014; Accepted 9 June 2014; Published 6 August 2014

Academic Editor: Fabio Farinati

Copyright (C) 2014 Rong Zhu et al. This is an open access article distributed under the Creative Commons Attribution License, which permits unrestricted use, distribution, and reproduction in any medium, provided the original work is properly cited.

Background. There have been many reports on des- $\gamma$-carboxy prothrombin (DCP) as a promising serum marker in the diagnosis of hepatocellular carcinoma (HCC); however, the results are inconsistent and even conflicting. Methods. This meta-analysis was performed to investigate the performance of DCP in the diagnosis of HCC. Following a systematic review of relevant studies, Meta-DiSc 1.4 software was used to extract data and to calculate the overall sensitivity, specificity, positive likelihood ratio (PLR), negative likelihood ratio (NLR), and diagnostic odds ratio (DOR). Data are presented as forest plots and summary receiver operating characteristic curve (SROC) analysis was used to summarize the overall test performance. Results. Twelve studies were included in our meta-analysis. The overall sensitivity, specificity, PLR, and NLR of DCP for the detection of HCC in the studies included were 71\% (95\%CI: 68\%-73\%), 84\% (95\%CI: 83\%-86\%), 6.48 (95\%CI: 4.22-9.93), and 0.33 (95\%CI: 0.25-0.43), respectively. The area under the SROC curve was 0.8930 and the $Q$ index was 0.8238 . Significant heterogeneity was found. Conclusion. This metaanalysis indicated that DCP had moderate diagnostic accuracy in HCC. Further studies with rigorous design, large sample size, and mmultiregional cooperation are needed in the future.

\section{Introduction}

Hepatocellular carcinoma (HCC) is the most common primary liver malignancy and the third most common cause of cancer death worldwide [1]. Approximately 500,000 new cases of HCC are reported each year and more than $75 \%$ of cases occur in the Asia- Pacific region, largely in association with chronic hepatitis B virus infection [2,3]. Each year an estimated 360000 patients living in the Far East countries (including China, Japan, and South Korea) die of liver cancer [4]. HCC usually develops in an already damaged liver, often in patients with cirrhosis. In most areas, chronic viral hepatitis caused by hepatitis $B$ virus or hepatitis $C$ virus is the major cause of HCC [5]. Usually, HCC is diagnosed at a late stage, and for these patients, the outcome of current medical treatments including chemotherapy, chemoembolization, ablation, and proton beam therapy is disappointing, with a 5 -year survival rate of less than 5\% [6]. Therefore, animal models of HCC should be established to facilitate research into the pathogenesis of HCC and to target therapies [7-9]. The detection of HCC at an early stage is very important. However, in most cases, early diagnosis of HCC is complex, because HCC is usually accompanied by inflammation and liver damage. The recommended screening strategy for patients over 35 years old, with hepatitis B virus (HBV) and (or) hepatitis $\mathrm{C}$ virus (HCV) infections, includes the determination of serum alpha-fetoprotein (AFP) levels and an abdominal ultrasound every 6 months to detect HCC at an early stage. Quantitative determination of serum AFP > $400 \mathrm{ng} / \mathrm{ml}$ lasting four weeks is valuable for the diagnosis of primary liver cancer, after excepting of active liver disease, embryonic gonad tumors and pregnancy cases [10]. However, 
due to low sensitivity and specificity, the clinical value of AFP is limited. In addition, AFP levels greater than $500 \mathrm{ng} / \mathrm{mL}$ are correlated with tumor size: $80 \%$ of small HCCs show no increase in AFP concentration [11]. Some patients with cirrhosis or hepatic inflammation have an elevated level of AFP without the presence of tumors [12]. Sex and features of chronic liver disease were identified as nontumor characteristics that influence serum AFP levels in patients with HCC [13]. And AFP serum levels have no prognostic meaning in well-compensated cirrhosis patients with single, small HCC treated with curative intent [14]. Therefore, it is necessary to identify new serum tumor markers to improve the early diagnosis of HCC.

Recent advances in genomics and proteomics identified a number of promising candidates which may provide superior utility over current tumor markers. Des- $\boldsymbol{\gamma}$-carboxy prothrombin (DCP) induced by vitamin K2 absence/antagonist$\mathrm{II}$ is also known as PIVKA-II (protein induced by vitamin $\mathrm{K}$ absence or antagonist-II). DCP is an abnormal prothrombin produced by HCC; it has completely lost the normal prothrombin function and may play an important role in the malignant proliferation of HCC. DCP is specific to HCC and less prone to elevation during chronic liver disease $[15,16]$. Many studies have found that the level of serum DCP in patients with benign and malignant liver diseases is significantly different, and its diagnostic sensitivity may be higher than commonly used HCC markers such as AFP; however, this remains controversial $[17,18]$. Serums DCP and AFP lack correlation and complement each other; therefore the combination of these markers may improve the diagnostic sensitivity for early HCC.

In this study, we performed a systematic review and metaanalysis to evaluate the role of DCP in the diagnosis of HCC.

\section{Methods}

2.1. Search Strategy. A systematic search was conducted by two investigators independently (Rong Zhu and Jing Yang). Studies were mainly searched in MEDLINE/PubMed, EMBASE, the Cochrane Central Register of Controlled Trials, CINAHL, Science Citation Index (ISI Web of Science), Chinese Biomedical Literature Database (CBM), and Chinese National Knowledge Infrastructure (CNKI) [19, 20]. In addition, the references of included articles and relevant published reports were hand searched. The search was confined to articles written in Chinese and English. No restriction was set on the year of publication. The latest search was updated in December 2012. Keywords used for the search were as follows: (1) DCP: DCP, des- $\gamma$-carboxyprothrombin, des-gamma-carboxy-prothrombin, PIVKA-II, and protein induced by vitamin K absence; and (2) HCC: HCC, hepatocellular carcinoma, liver cell carcinoma, liver cancer, and hepatic cell carcinoma. Both free text and a MeSH search for keywords were employed.

2.2. Criteria for Selection. Articles were suitable if the following criteria were satisfied: (1) eligible studies were clinical research articles that used DCP as a serum marker for
HCC; (2) the diagnosis of HCC was usually established by histopathological examination or ultrasound magnetic resonance imaging (MRI) and computer tomography (CT) when either of these techniques showed a nodule with arterial hypervascularization $>2 \mathrm{~cm}$ [21]; (3) eligible studies should provide the sensitivity and specificity of DCP; and (4) the data were not included in a duplicate publication.

2.3. Criteria for Exclusion. Articles were excluded using the following criteria: (1) studies with ambiguous diagnostic criteria; (2) studies that evaluated serum DCP levels using messenger RNA, DNA, or DNA polymorphisms; (3) studies without sufficient information to make a judgment; and (4) studies that were published as reviews, letters, case reports, editorials, or comments.

2.4. Selection of Studies. The title and abstract of the studies based on the search results were read thoroughly to confirm eligibility and the full text of potentially eligible studies was then retrieved for further assessment. Doubts were discussed with a third investigator. The authors were contacted for further study details if necessary.

2.5. Data Extraction. Data were extracted from full length articles including the use of a predesigned form by two investigators (Rong Zhu and Jing Yang) independently. Disagreements were resolved by discussion. The extracted information included name of the first author, year of publication, journal, study design, diagnostic criteria, number of patients, ethnicity, type of assay used for the biomarkers, and cutoff values and raw data (the number of true positive, false positive, false negative, and true negative subjects).

2.6. Assessment of Methodological Quality. The quality of each study was assessed according to the QUADAS (quality assessment of studies of diagnostic accuracy included in systematic reviews) checklist recommended by the Cochrane Collaboration. Each of the 14 items in the QUADAS checklist was scored as "yes," "no," or "unclear" [22].

2.7. Indices of Diagnostic Efficacy. The indices of diagnostic efficacy included sensitivity, specificity, diagnostic odds ratio (DOR), symmetric summary receiver operating characteristic (SROC) curve, and the $Q^{*}$ index.

2.8. Data Analysis. Using the Midas model for Stata (version 11.0), funnel plots were constructed and $P$ values were calculated. Publication bias existed when a $P$ value $<0.05$ was observed. Meta-DiSc 1.4 software was used to summarize the pooled sensitivity, specificity, PLR, NLR, and DOR and to construct a summary receiver operating characteristic (SROC) curve to calculate area under the curve. As a potential cause of heterogeneity, the threshold effect was tested using the Spearman correlation coefficient. Heterogeneity induced by other factors, such as sensitivity and specificity, was assessed using the chi-square test. PLR and NLR were assessed by Cochrane's $Q$ test. Heterogeneity was investigated 
TABLE 1: Main characteristics of the studies included in the meta-analysis.

\begin{tabular}{|c|c|c|c|c|c|c|c|c|c|c|}
\hline Number & Study & $\mathrm{TP}$ & $\mathrm{FP}$ & $\mathrm{FN}$ & $\mathrm{TN}$ & $N$ & Assay type & $\begin{array}{c}\text { DCP cutoff } \\
\text { value } \\
(\mathrm{mAU} / \mathrm{mL})\end{array}$ & Ethnicity & Small HCC \\
\hline 1 & Baek et al., 2009 [23] & 189 & 32 & 38 & 68 & 327 & ELISA & 40 & Asian & No \\
\hline 2 & Cui et al., 2003 [24] & 64 & 13 & 56 & 77 & 210 & EIA & 40 & Asian & No \\
\hline 3 & Durazo et al., 2008 [25] & 125 & 14 & 19 & 82 & 240 & ELISA & 84 & Asian & No \\
\hline 4 & Kuromatsu et al., 1997 [26] & 58 & 6 & 71 & 77 & 212 & ELISA & 40 & Asian & No \\
\hline 5 & Lok et al., 2010 [27] & 29 & 11 & 10 & 66 & 116 & EIA & 40 & Caucasian & Yes \\
\hline 6 & Marrero et al., 2003 [28] & 50 & 5 & 5 & 99 & 159 & ELISA & 125 & Caucasian & No \\
\hline 7 & Marrero et al., 2009 [29] & 310 & 125 & 109 & 292 & 836 & ELISA & 150 & Caucasian & No \\
\hline 8 & Okuda, 1999 [30] & 36 & 9 & 24 & 108 & 177 & ELISA & 40 & Asian & No \\
\hline 9 & Sassa et al., 1999 [31] & 27 & 2 & 34 & 132 & 195 & ECL & 40 & Asian & Yes \\
\hline 10 & Volk et al., 2007 [17] & 72 & 12 & 12 & 157 & 253 & ELISA & 150 & Caucasian & No \\
\hline 11 & Wang et al., 2005 [32] & 47 & 9 & 14 & 57 & 127 & ELISA & 40 & Asian & No \\
\hline 12 & Yoon et al., 2009 [33] & 55 & 3 & 51 & 97 & 206 & ELISA & 40 & Asian & No \\
\hline
\end{tabular}

TP: true positive; FP: false positive; FN: false negative; TN: true negative. Small HCC: all tumors were $\leq 3 \mathrm{~cm}$ in diameter.

using the Higgins $\left(I^{2}\right)$ estimate. When the $I^{2}$ value was $<25 \%$, this represented low heterogeneity; when the $I^{2}$ value was $>25 \%$ and $<50 \%$, this indicated moderate heterogeneity; and when the $I^{2}$ value was $>50 \%$, this suggested high heterogeneity. The fixed effects model was used when no heterogeneity existed and the random effects model was used to collectively analyze the accuracy indicators. The results are presented with the corresponding $95 \%$ confidence intervals (CI) and the significance level $\alpha$ was 0.05 . Meta-regression was also performed to explain the source of the observed heterogeneity.

\section{Results}

3.1. Characteristics of the Selected Studies. A total of 155 studies were identified, of which 12 [17, 23-33] were considered suitable for inclusion in the analysis after excluding summaries, case reports, duplicates, and unsuitable studies, and all were English publications. Of these 12 studies, only 2 were perspective studies [27,33] and 10 were retrospective studies. As shown in Table 1,12 studies involving 3,058 patients were included for meta-analysis; 1,505 of these patients had HCC and 1553 did not. A flow diagram of the study selection process is shown in Figure 1.

The characteristics of each study are shown in Table 1. The number of patients in each of the 12 studies was greater than 100, with little difference in characteristics between the studies. The DCP cutoff values in 8 studies were $40 \mathrm{mAU} / \mathrm{mL}$ $[21,23,24,26,27,30,32,33]$. The ethnicity in 4 studies was Caucasian [27-30] and was Asian in the remaining studies.

3.2. Quality of the Studies. The results of the QUADAS assessment are shown in Table 2. Five studies scored A $[17,23,30,32,33], 3$ studies scored B $[26,27,29]$, and 4 studies scored C $[24,25,28,31]$. Various types of diseases were compared and analyzed in 8 studies
$[17,23,26,27,29,30,32,33]$, while 4 other studies did not completely cover the control diseases; all studies established the gold standard (including histopathological examination and iconography evidence), which accurately distinguished between malignant and benign diseases; three studies did not supply sufficient information to determine whether blood samples were collected before the intervention $[24,26,29]$; in 7 studies the disease status was confirmed by the reference standard in all patients without the results of DCP and AFP $[17,23,26,29,30,32,33]$, and another 4 studies did not provide sufficient information. Two studies did not provide an explanation as to why patients quit the trials $[26,29]$. All studies provided a detailed description of the method used to determine serum DCP.

\subsection{Results of Statistical Analysis}

3.3.1. Publication Bias Analysis. Deeks funnel plots were used to examine publication bias and are shown in Figure 2. A $P$ value $<0.05$ showed that there was publication bias in the 12 studies.

3.3.2. Heterogeneity Analysis. As differences in sensitivity, specificity, and DOR, which are caused by different cutoff values, may produce a threshold effect, it is necessary to assess the presence of a threshold effect. The ROC scatter plot would show a typical "shoulder arm" pattern and Spearman correlation analysis would show a strong positive correlation if a threshold effect existed. In this study, the ROC scatter plot obtained using Meta-DiSc 1.4 software was not the typical "shoulder arm" pattern (Figure 3). The Spearman correlation coefficient $(r s)$ value was 0.336 and the $P$ value was 0.286 , suggesting that there was no threshold effect.

After testing for heterogeneity caused by other sources, the results showed that sensitivity $\left(P=0.000, I^{2}=93.1 \%\right)$, 


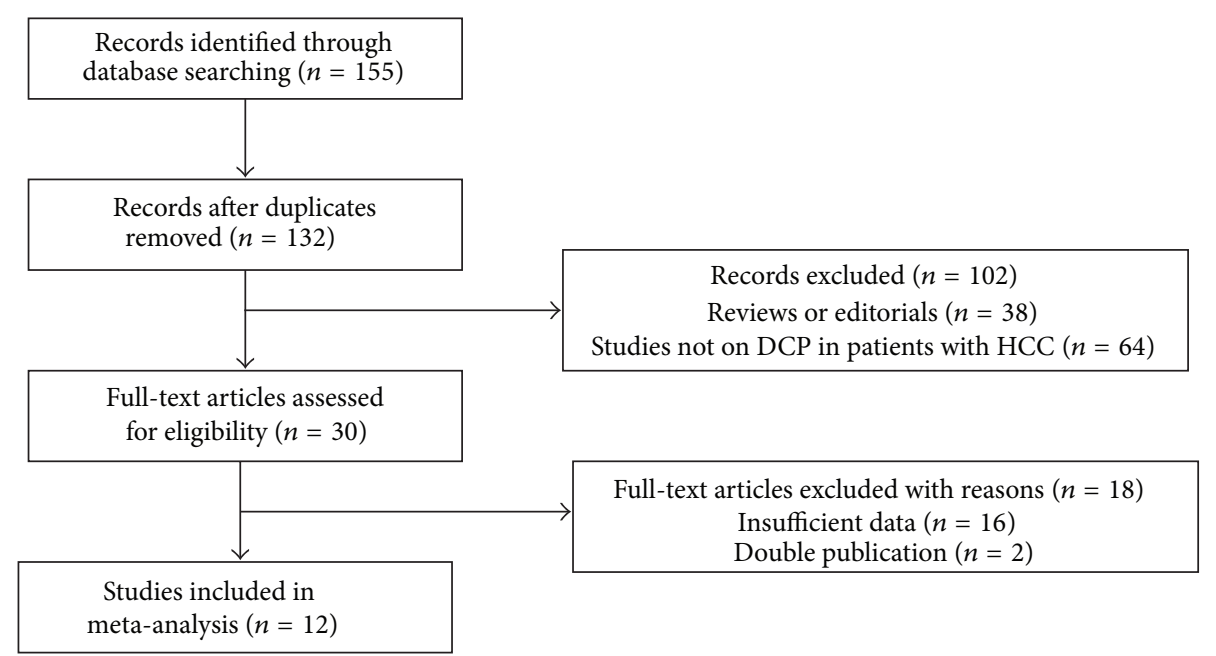

FIGURE 1: Study selection.

TABLE 2: Summary of methodological quality of the included studies on the basis of the review authors' judgments on the 14 items in the QUADAS checklist for each study.

\begin{tabular}{|c|c|c|c|c|c|c|c|c|c|c|c|c|}
\hline \multirow{2}{*}{ QUADAS } & \multicolumn{12}{|c|}{ Number } \\
\hline & 1 & 2 & 3 & 4 & 5 & 6 & 7 & 8 & 9 & 10 & 11 & 12 \\
\hline Representative patient spectrum? & $\mathrm{Y}$ & $\mathrm{N}$ & $\mathrm{N}$ & $\mathrm{Y}$ & $\mathrm{Y}$ & $\mathrm{N}$ & $\mathrm{Y}$ & $\mathrm{Y}$ & $\mathrm{N}$ & $\mathrm{Y}$ & $\mathrm{Y}$ & $\mathrm{Y}$ \\
\hline Selection criteria & $\mathrm{Y}$ & $\mathrm{Y}$ & $\mathrm{Y}$ & $\mathrm{Y}$ & $\mathrm{Y}$ & $\mathrm{Y}$ & $\mathrm{Y}$ & $\mathrm{Y}$ & $\mathrm{Y}$ & $\mathrm{Y}$ & $\mathrm{Y}$ & $\mathrm{Y}$ \\
\hline Acceptable reference standard? & $\mathrm{Y}$ & $\mathrm{Y}$ & $\mathrm{Y}$ & $\mathrm{Y}$ & $\mathrm{Y}$ & $\mathrm{Y}$ & $\mathrm{Y}$ & $\mathrm{Y}$ & $\mathrm{Y}$ & $\mathrm{Y}$ & $\mathrm{Y}$ & $\mathrm{Y}$ \\
\hline Acceptable delay between tests? & $\mathrm{Y}$ & NR & $\mathrm{Y}$ & NR & $\mathrm{Y}$ & $\mathrm{Y}$ & NR & $\mathrm{Y}$ & $\mathrm{Y}$ & $\mathrm{Y}$ & $\mathrm{Y}$ & $\mathrm{Y}$ \\
\hline Partial verification avoided? & $\mathrm{Y}$ & $\mathrm{Y}$ & $\mathrm{Y}$ & $\mathrm{Y}$ & $\mathrm{Y}$ & $\mathrm{Y}$ & $\mathrm{Y}$ & $\mathrm{Y}$ & $\mathrm{Y}$ & $\mathrm{Y}$ & $\mathrm{Y}$ & $\mathrm{Y}$ \\
\hline Differential verification avoided? & $\mathrm{Y}$ & $\mathrm{Y}$ & $\mathrm{Y}$ & $\mathrm{Y}$ & $\mathrm{Y}$ & $\mathrm{Y}$ & $\mathrm{Y}$ & $\mathrm{Y}$ & $\mathrm{Y}$ & $\mathrm{Y}$ & $\mathrm{Y}$ & $\mathrm{Y}$ \\
\hline Incorporation avoided? & $\mathrm{Y}$ & $\mathrm{Y}$ & $\mathrm{Y}$ & $\mathrm{Y}$ & $\mathrm{Y}$ & $\mathrm{Y}$ & $\mathrm{Y}$ & $\mathrm{Y}$ & $\mathrm{Y}$ & $\mathrm{Y}$ & $\mathrm{Y}$ & $\mathrm{Y}$ \\
\hline Index test execution & $\mathrm{Y}$ & $\mathrm{Y}$ & $\mathrm{Y}$ & $\mathrm{Y}$ & $\mathrm{Y}$ & $\mathrm{Y}$ & $\mathrm{Y}$ & $\mathrm{Y}$ & $\mathrm{Y}$ & $\mathrm{Y}$ & $\mathrm{Y}$ & $\mathrm{Y}$ \\
\hline Reference standard execution & $\mathrm{Y}$ & $\mathrm{Y}$ & $\mathrm{Y}$ & $\mathrm{Y}$ & $\mathrm{Y}$ & $\mathrm{Y}$ & $\mathrm{Y}$ & $\mathrm{Y}$ & $\mathrm{Y}$ & $\mathrm{Y}$ & $\mathrm{Y}$ & $\mathrm{Y}$ \\
\hline Reference standard results blinded? & $\mathrm{Y}$ & $\mathrm{Y}$ & $\mathrm{Y}$ & $\mathrm{Y}$ & $\mathrm{Y}$ & $\mathrm{Y}$ & $\mathrm{Y}$ & $\mathrm{Y}$ & $\mathrm{Y}$ & $\mathrm{Y}$ & $\mathrm{Y}$ & $\mathrm{Y}$ \\
\hline Index test results blinded? & $\mathrm{Y}$ & NR & NR & $\mathrm{Y}$ & NR & NR & $\mathrm{Y}$ & $\mathrm{Y}$ & $\mathrm{N}$ & $\mathrm{Y}$ & $\mathrm{Y}$ & $\mathrm{Y}$ \\
\hline Relevant clinical information? & $\mathrm{Y}$ & $\mathrm{Y}$ & $\mathrm{Y}$ & $\mathrm{Y}$ & $\mathrm{Y}$ & $\mathrm{Y}$ & $\mathrm{Y}$ & $\mathrm{Y}$ & $\mathrm{Y}$ & $\mathrm{Y}$ & $\mathrm{Y}$ & $\mathrm{Y}$ \\
\hline Uninterpretable results reported? & $\mathrm{Y}$ & $\mathrm{Y}$ & $\mathrm{Y}$ & $\mathrm{Y}$ & $\mathrm{Y}$ & $\mathrm{Y}$ & $\mathrm{Y}$ & $\mathrm{Y}$ & $\mathrm{Y}$ & $\mathrm{Y}$ & $\mathrm{Y}$ & $\mathrm{Y}$ \\
\hline Withdrawals explained? & $\mathrm{Y}$ & $\mathrm{Y}$ & $\mathrm{Y}$ & NR & $\mathrm{Y}$ & $\mathrm{Y}$ & NR & $\mathrm{Y}$ & $\mathrm{Y}$ & $\mathrm{Y}$ & $\mathrm{Y}$ & $\mathrm{Y}$ \\
\hline Quality of the studies & A & $\mathrm{C}$ & $\mathrm{C}$ & $\mathrm{B}$ & B & $\mathrm{C}$ & B & A & $\mathrm{C}$ & $\mathrm{A}$ & A & A \\
\hline
\end{tabular}

specificity $\left(P=0.000, I^{2}=92.9 \%\right)$, PLR (Cochrane $Q=$ 98.92, $\left.P=0.000, I^{2}=88.9 \%\right)$, NLR (Cochrane $Q=119.13$, $P=0.000, I^{2}=90.8 \%$ ), and DOR (Cochrane $Q=73.88$, $\left.P=0.000, I^{2}=85.1 \%\right)$ in the included studies showed high heterogeneity. Metaregression analysis revealed that the sources of heterogeneity were correlated with quality of the studies, type of assay used for the biomarkers, ethnicity, tumor size, and study design; however, individual factors were not associated with heterogeneity (Table 3 ), suggesting that the influencing factors are complex.

3.3.3. Meta-Analysis. The DerSimonian-Laird (random effects) model was used to calculate the pooled value. The area under the curve (AUC) of the summary receiver operating characteristic curve (SROC) was $0.8930, \mathrm{SE}=0.0201$, and $Q^{*}=0.8238$ (Figure 4 ). The pooled sensitivity and specificity were $71 \%$ (95\%CI: 68\%-73\%) (Figure 5(a)) and 84\% (95\%CI: $83 \%-86 \%$ ) (Figure 5(b)), respectively. The pooled PLR and NLR were 6.48 (95\%CI: 4.22-9.93) (Figure 5(c)) and 0.33 (95\%CI: 0.25-0.43) (Figure 5(d)) and the pooled DOR was 21.86 (95\%CI: 12.38-38.60) (Figure 6), respectively.

3.3.4. Sensitivity Analysis. A sensitivity analysis was carried out using the following 4 criteria to examine the stability of the meta-analysis: (1) remove 7 studies of poor quality according to the QUADAS assessment; (2) remove 3 studies which did not use ELISA detection methods; (3) patients were divided into two categories according to ethnicity: 8 studies included Asian patients and 4 studies included Caucasian patients; (4) studies included were divided into two groups: 2 perspective studies and 10 retrospective studies. The results showed that there was no significant difference in 


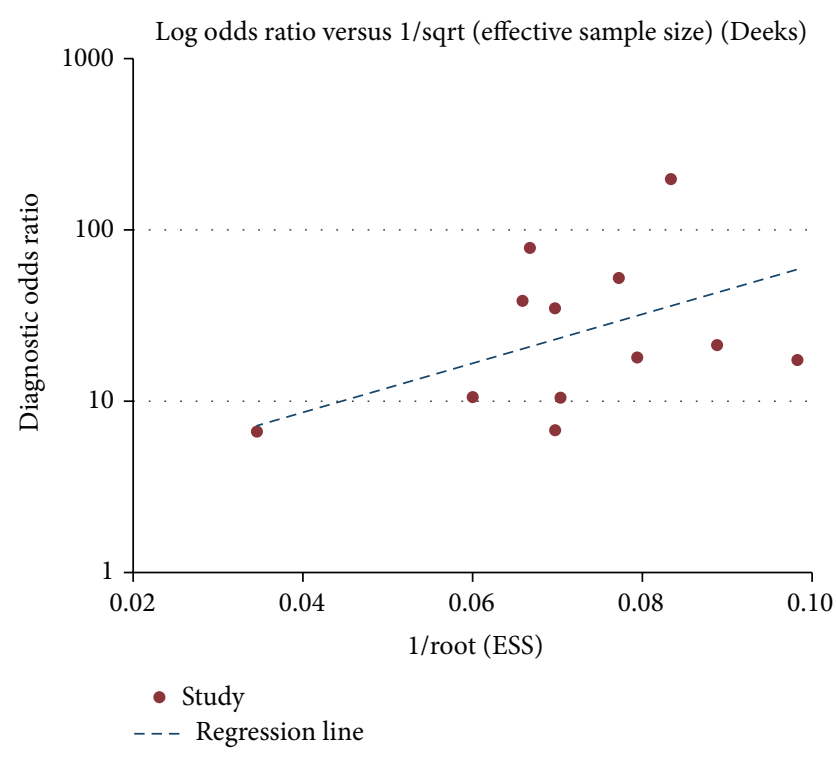

FIGURE 2: Deeks funnel plots.

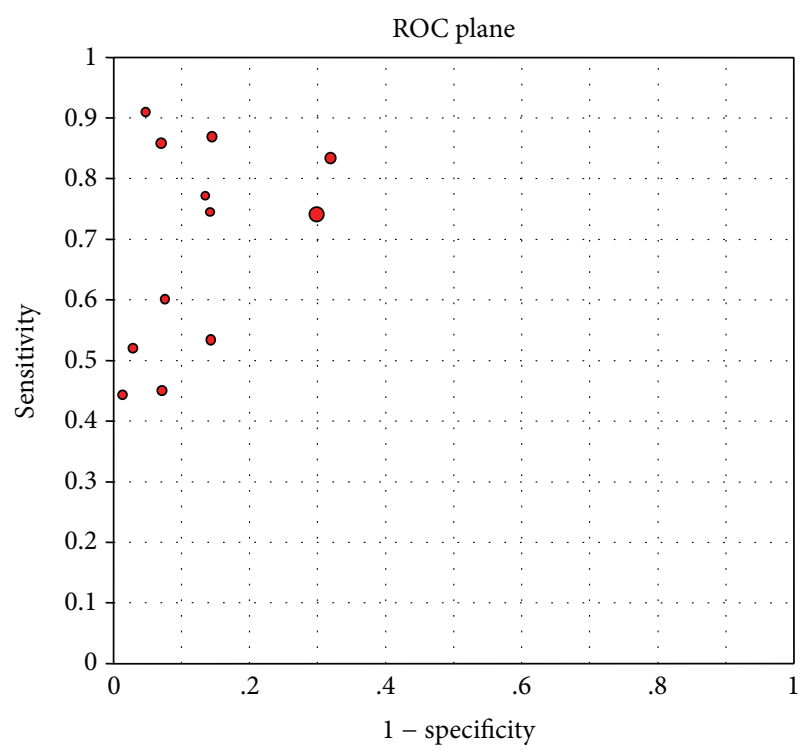

FIGURE 3: ROC scatter plot of the 12 included studies.

the pooled index between the 5 studies which scored $\mathrm{A}$ in the 9 studies which used ELISA detection methods and in the 12 studies included. In addition, these studies had overlapping confidence intervals. However, the DOR of the Caucasian studies was higher than that of the Asian studies (Asian: DOR: 17.39, AUC: 0.8761, $Q^{*}$ : 0.8066; Caucasian: DOR: 34.44, AUC: $\left.0.9209, Q^{*}: 0.8544\right)$ (Table 4).

In perspective studies and retrospective studies, there was no significant difference in DOR, but there was a difference in sensitivity and specificity.
TABLE 3: Metaregression analysis of diagnostic accuracy.

\begin{tabular}{lcccc}
\hline Var. & Coeff. & Std. err. & $P$ value & RDOR \\
\hline Quality & -0.354 & 0.5196 & 0.5214 & 0.70 \\
Assay & -1.117 & 1.4138 & 0.4596 & 0.33 \\
Ethnicity & -0.625 & 0.8972 & 0.5120 & 0.54 \\
Small HCC & 0.994 & 2.0079 & 0.6383 & 2.70 \\
\hline
\end{tabular}

\section{Discussion}

Early diagnosis of HCC, which is directly related to therapeutic effects and prognosis, is very important. The most commonly used screening strategy in patients with cirrhosis is the determination of serum alpha-fetoprotein (AFP) levels. However, in the majority of patients with small HCCs, the serum AFP level does not increase significantly [34, 35]. Due to the low accuracy of AFP, it is necessary to explore other serum markers with better diagnostic sensitivity and heterogeneity for HCC. Des- $\gamma$-carboxy prothrombin (DCP), induced by vitamin $\mathrm{K} 2$ absence/antagonist-II, is an abnormal prothrombin produced by HCC. DCP is specific to HCC and less prone to elevation during chronic liver disease. Therefore, DCP is a potential serum marker of HCC and may be important in the early diagnosis of HCC [36]. In this study, we attempted to review the literature and perform a metaanalysis to evaluate the role of DCP in the diagnosis of HCC.

To determine the value of using DCP as a biomarker of HCC, 12 studies fulfilling the inclusion criteria which included 3058 subjects, 1505 with HCC and 1553 without HCC, were evaluated. Heterogeneity (with the exception of the threshold effect) was found in these studies. The pooled sensitivity and specificity were 71\% (95\%CI: 68\%-73\%) and 84\% (95\%CI: 83\%-86\%), respectively. The pooled PLR and NLR were 6.48 (95\%CI: 4.22-9.93) and 0.33 (95\%CI: $0.25-$ 0.43 ) and the pooled DOR was 21.86 (95\%CI: $12.38-38.60)$, respectively. These results suggest that the accuracy of DCP in the diagnosis of HCC may not be as high as previously described in some studies. In the study by Marrero and colleagues [28], the sensitivity and specificity were $91 \%$ and $95 \%$, respectively.

The likelihood ratio is a composite index of sensitivity and specificity. A LR $>10$ or $<0.1$ results in significant and conclusive shifts from pretest to posttest probability, essentially determining or excluding the diagnosis; 5 to 10 or 0.1 to 0.2 results in moderate shifts from pretest to posttest probability; 2 to 5 or 0.2 to 0.5 results in a small change in probability; 1 to 2 or 0.5 to 1 results in no change in probability [12]. The PLR in this study was 6.48 , indicating that patients with HCC had more than a 6 -fold higher chance of a positive DCP assay compared to patients without HCC. The PLR did not reach 10; therefore, the diagnostic accuracy of DCP for HCC was moderate. The NLR was 0.33 , which indicated that if the DCP assay was negative, the probability of these patients developing HCC was approximately $33 \%$. Thus DCP-negative results may not be used to exclude HCC.

The QUADAS tool was used to evaluate the included studies; the results showed that five studies scored A, 3 studies scored $\mathrm{B}$, and 4 studies scored $\mathrm{C}$, indicating that the quality 


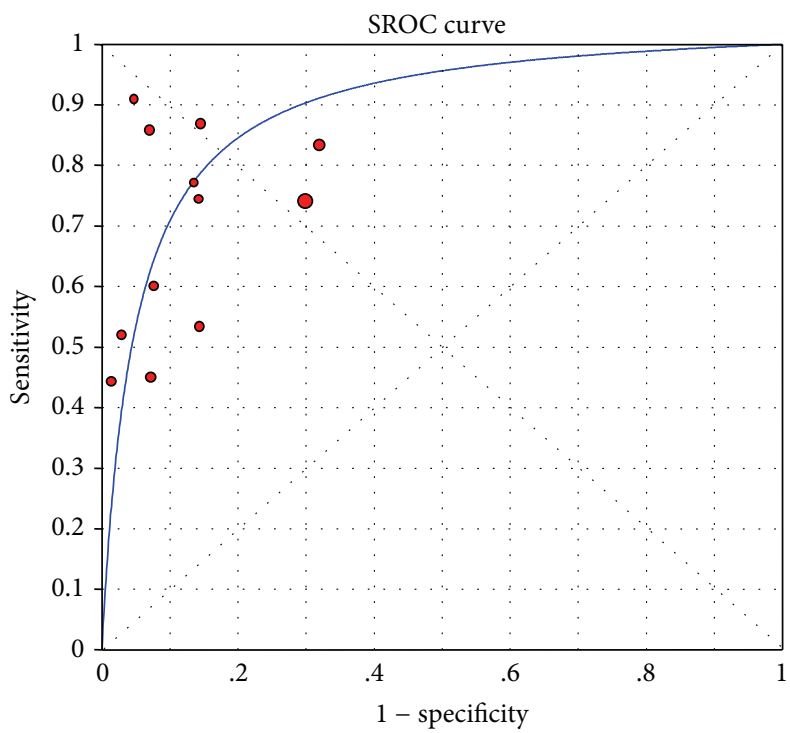

Symmetric SROC

AUC $=0.8930$

$\mathrm{SE}(\mathrm{AUC})=0.0201$

$Q^{*}=0.8238$

$\operatorname{SE}\left(Q^{*}\right)=0.0210$

FIgURE 4: SROC of the 12 included studies.

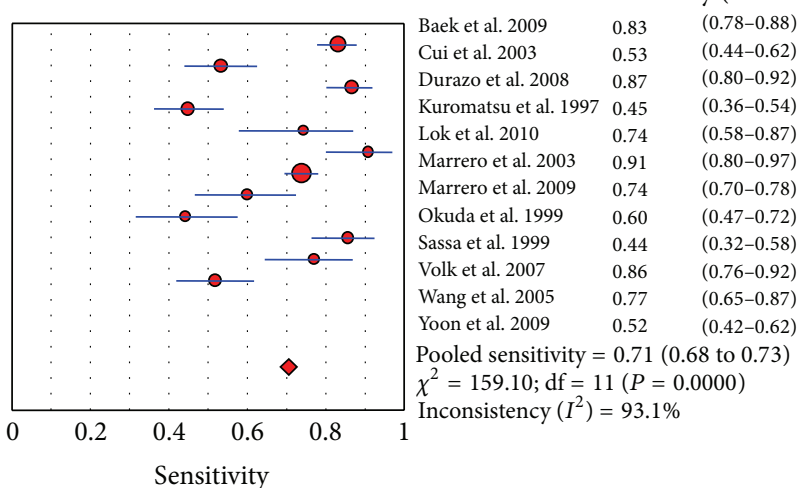

(a)

Positive LR (95\% CI)

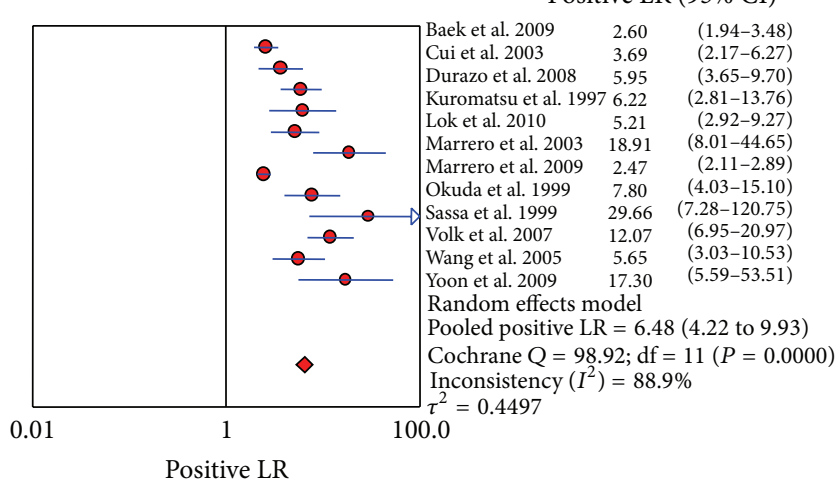

(c)
Specificity $(95 \%$ CI)

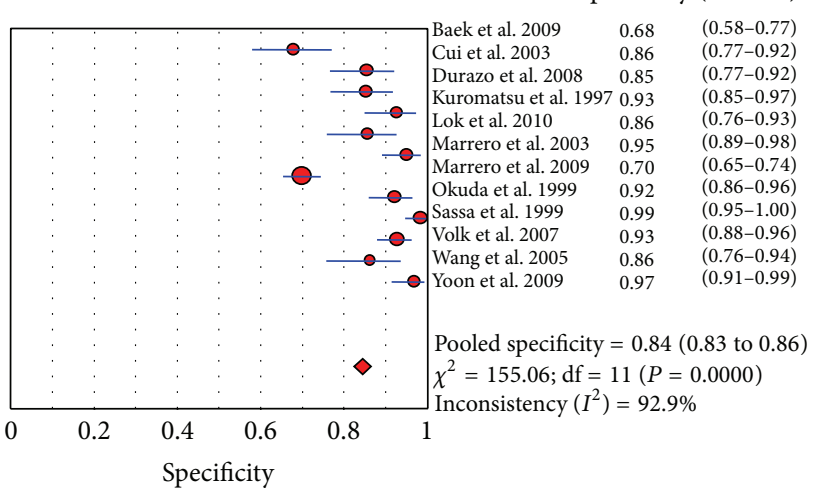

(b)

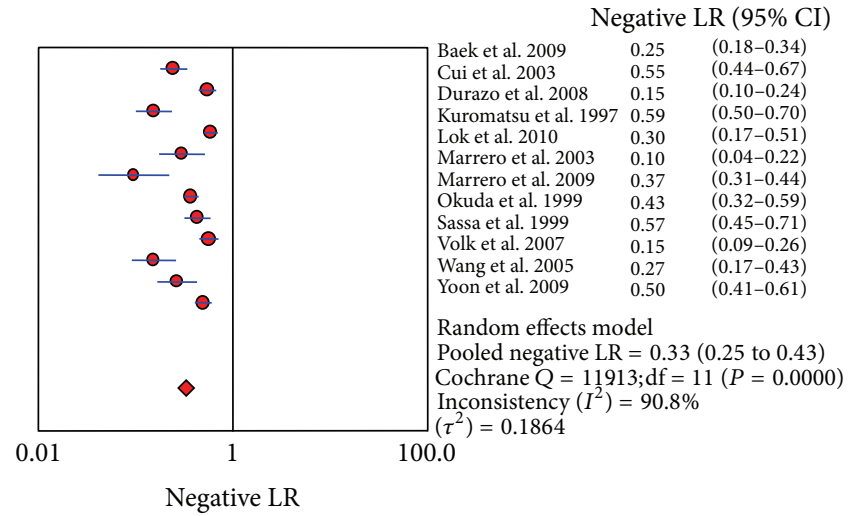

(d)

FIGURE 5: Forest map of the meta-analysis of each index: (a) sensitivity, (b) specificity, (c) PLR, and (d) NLR.

of the included studies was quite different. The threshold effect according to heterogeneity tests of the included studies was not observed; sensitivity, specificity, PLR, NLR, and DOR among the included studies showed high heterogeneity, which may have been caused by the quality of the studies, type of assay used for the biomarkers, ethnicity, tumor size, study design, and other aspects. However, metaregression analysis showed that the above-mentioned factors do not significantly 
TABLE 4: Results of the sensitivity analysis using 3 criteria.

\begin{tabular}{|c|c|c|c|c|c|c|c|c|}
\hline $\begin{array}{l}\text { Analytical } \\
\text { perspective }\end{array}$ & Quantity & $\begin{array}{c}\text { SEN } \\
(95 \% \mathrm{CI}) \\
\end{array}$ & $\begin{array}{c}\text { SPE } \\
(95 \% \mathrm{CI}) \\
\end{array}$ & $\begin{array}{c}\text { PLR } \\
(95 \% \mathrm{CI}) \\
\end{array}$ & $\begin{array}{c}\text { NLR } \\
(95 \% \mathrm{CI}) \\
\end{array}$ & $\begin{array}{c}\text { DOR } \\
(95 \% \mathrm{CI}) \\
\end{array}$ & AUC & $Q^{*}$ \\
\hline Included studies & 12 & $\begin{array}{c}0.71 \\
(0.68,0.73)\end{array}$ & $\begin{array}{c}0.84 \\
(0.83,0.86)\end{array}$ & $\begin{array}{c}6.48 \\
(4.22,9.93)\end{array}$ & $\begin{array}{c}0.33 \\
(0.25,0.43)\end{array}$ & $\begin{array}{c}21.86 \\
(12.38,38.60)\end{array}$ & 0.8930 & 0.8238 \\
\hline Studies scored A & 5 & $\begin{array}{c}0.74 \\
(0.70,0.78)\end{array}$ & $\begin{array}{c}0.88 \\
(0.85,0.91)\end{array}$ & $\begin{array}{c}7.06 \\
(3.27,15.21)\end{array}$ & $\begin{array}{c}0.30 \\
(0.20,0.47)\end{array}$ & $\begin{array}{c}24.56 \\
(11.55,52.23)\end{array}$ & 0.9008 & 0.8321 \\
\hline $\begin{array}{l}\text { Used ELISA } \\
\text { detection methods }\end{array}$ & 9 & $\begin{array}{c}0.73 \\
(0.71,0.76)\end{array}$ & $\begin{array}{c}0.83 \\
(0.81,0.85)\end{array}$ & $\begin{array}{c}6.48 \\
(3.91,10.73)\end{array}$ & $\begin{array}{c}0.29 \\
(0.20,0.41)\end{array}$ & $\begin{array}{c}24.29 \\
(12.11,48.70)\end{array}$ & 0.9001 & 0.8313 \\
\hline \multicolumn{9}{|l|}{ Ethnicity } \\
\hline Asian & 8 & $\begin{array}{c}0.66 \\
(0.63,0.69)\end{array}$ & $\begin{array}{c}0.89 \\
(0.86,0.91)\end{array}$ & $\begin{array}{c}6.16 \\
(3.83,9.91)\end{array}$ & $\begin{array}{c}0.39 \\
(0.29,0.52)\end{array}$ & $\begin{array}{c}17.39 \\
(10.61,28.51)\end{array}$ & 0.8761 & 0.8066 \\
\hline Caucasian & 4 & $\begin{array}{c}0.77 \\
(0.74,0.81)\end{array}$ & $\begin{array}{c}0.80 \\
(0.77,0.83)\end{array}$ & $\begin{array}{c}7.06 \\
(2.54,19.63)\end{array}$ & $\begin{array}{c}0.22 \\
(0.12,0.40)\end{array}$ & $\begin{array}{c}34.44 \\
(7.02,168.96)\end{array}$ & 0.9209 & 0.8544 \\
\hline \multicolumn{9}{|l|}{ Type } \\
\hline Perspective & 2 & $\begin{array}{c}0.58 \\
(0.49,0.66)\end{array}$ & $\begin{array}{c}0.92 \\
(0.87,0.96)\end{array}$ & $\begin{array}{c}8.78 \\
(2.30,33.43)\end{array}$ & $\begin{array}{c}0.41 \\
(0.24,0.69)\end{array}$ & $\begin{array}{c}22.77 \\
(10.72,48.33)\end{array}$ & 0.5000 & 0.5000 \\
\hline Retrospective & 10 & $\begin{array}{c}0.72 \\
(0.69,0.74)\end{array}$ & $\begin{array}{c}0.84 \\
(0.81,0.85)\end{array}$ & $\begin{array}{c}6.17 \\
(3.90,9.76)\end{array}$ & $\begin{array}{c}0.31 \\
(0.23,0.43)\end{array}$ & $\begin{array}{c}21.62 \\
(11.41,40.99)\end{array}$ & 0.8875 & 0.8181 \\
\hline
\end{tabular}

SEN: sensitivity; SPE: specificity; PLR: positive likelihood ratio; NLR: negative likelihood ratio; DOR: diagnostic odds ratio; AUC: area under curve.

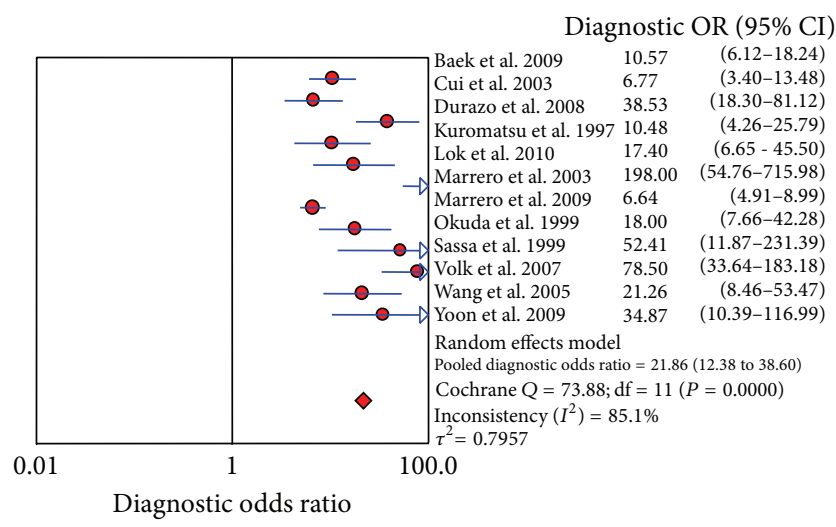

FIGURE 6: Forest map of DOR.

affect heterogeneity, suggesting that the influencing factors are complex. In the sensitivity analysis, quality of the studies and type of DCP assay had no significant effect on the results of the evaluation, and most results had overlapping confidence intervals. After dividing the 12 included studies into two categories according to ethnicity, the index in the Caucasian category was better than that in the Asian category, with the exception of specificity, indicating that the value of DCP in the diagnosis of HCC may be different between races. We guess that the differences in etiology of HCC between Asians and Caucasians may lead to this result. In Asians, chronic viral hepatitis due to hepatitis B virus (HBV) or hepatitis $\mathrm{C}$ virus (HCV) is the main cause of HCC; however, in Caucasians, alcoholic cirrhosis is the main cause of HCC. However, in our meta-analysis, there were only 8 studies that included Asian patients and 4 studies that included Caucasian patients; we need more clinical studies to prove this speculate.
In this study, a rigorous and rational search strategy, inclusion criteria, and statistical analyses were used to systematically and comprehensively analyze the value of serum DCP in the diagnosis of HCC. However, this study had many limitations. First, we suggest that a pathogenesis of HCC should be established and improved in the near future, to facilitate research into the molecular markers, diagnosis of HCC, and target therapies [7-9, 19, 20, 37-41]. Second, due to the poor quality of the included studies, the meta-analysis was affected by publication bias. Third, most of the studies were retrospective and the number of prospective studies was small. The number of patients with early stage HCC was not mentioned or too small to investigate the value of DCP in the diagnosis of early HCC.

\section{Conclusions}

In summary, the serum marker, DCP, showed a strong positive correlation with HCC, and the meta-analysis indicated that DCP had a moderate diagnostic accuracy for HCC. The measurement of DCP may be an optional method in the diagnosis of HCC. More studies with a rigorous design, large sample size, and multiregional cooperation are needed to obtain further evidence on the value of DCP in HCC diagnosis.

\section{Conflict of Interests}

The authors declare that they have no competing interests.

\section{Authors' Contribution}

Rong Zhu and Jing Yang contributed equally to this paper. 


\section{Acknowledgment}

This study was supported by the National Natural Science Foundation of China (Grant no. 81270515).

\section{References}

[1] J. Ferlay, H. R. Shin, F. Bray et al., "Estimates of worldwide burden of cancer in 2008: GLOBOCAN 2008," International Journal of Cancer, vol. 127, pp. 2918-2927, 2008.

[2] K. A. McGlynn, L. Tsao, A. W. Hsing, S. S. Devesa, and J. F. Fraumeni Jr., "International trends and patterns of primary liver cancer," International Journal of Cancer, vol. 94, no. 2, pp. 290296, 2001.

[3] G. D. Kirk, O. A. Lesi, M. Mendy et al., "The Gambia liver cancer study: infection with hepatitis $\mathrm{B}$ and $\mathrm{C}$ and the risk of hepatocellular carcinoma in West Africa," Hepatology, vol. 39, no. 1, pp. 211-219, 2004.

[4] T. Umemura and K. Kiyosawa, "Epidemiology of hepatocellular carcinoma in Japan," Hepatology Research, vol. 37, supplement 2, pp. S95-S100, 2007.

[5] S. Sherlock, "Viruses and hepatocellular carcinoma," Gut, vol. 35, no. 6, pp. 828-832, 1994.

[6] A. S. Befeler and A. M. di Bisceglie, "Hepatocellular carcinoma: diagnosis and treatment," Gastroenterology, vol. 122, no. 6, pp. 1609-1619, 2002.

[7] L. Jie, W. Fan, D. Weiqi et al., “The hippo-yes association protein pathway in liver cancer," Gastroenterology Research and Practice, vol. 2013, Article ID 187070, 7 pages, 2013.

[8] F. Wang, L. He, W. Dai et al., "Salinomycin inhibits proliferation and induces apoptosis of human hepatocellular carcinoma cells in vitro and in vivo," PLoS One, vol. 7, no. 12, Article ID e50638, 2012.

[9] W. Dai, F. Wang, L. He et al., "Guo C.Genistein inhibits hepatocellular carcinoma cell migration by reversing the epithelialmesenchymal transition: partial mediation by the transcription factor NFAT1," Molecular Carcinogenesis, 2013.

[10] G. Bertino, A. Ardiri, M. Malaguarnera, G. Malaguarnera, N. Bertino, and G. S. Calvagno, "Hepatocellualar carcinoma serum markers," Seminars in Oncology, vol. 39, no. 4, pp. 410-433, 2012.

[11] R. Saffroy, P. Pham, M. Reffas, M. Takka, A. Lemoine, and B. Debuire, "New perspectives and strategy research biomarkers for hepatocellular carcinoma," Clinical Chemistry and Laboratory Medicine, vol. 45, no. 9, pp. 1169-1179, 2007.

[12] R. Jaeschke, G. H. Guyatt, and D. L. Sackett, "User's guides to the medical literature: III. How to use an article about a diagnostic test: B. What are the results and will they help me in caring for my patients?" The Journal of the American Medical Association, vol. 271, no. 9, pp. 703-707, 1994.

[13] E. G. Giannini, G. Sammito, F. Farinati et al., "Determinants of alpha-fetoprotein levels in patients with hepatocellular carcinoma: implications for its clinical use," Cancer, vol. 120, no. 14, pp. 2150-2157, 2014.

[14] E. G. Giannini, S. Marenco, G. Borgonovo et al., “ $\alpha$-fetoprotein has no prognostic role in small hepatocellular carcinoma identified during surveillance in compensated cirrhosis," Hepatology, vol. 56, no. 4, pp. 1371-1379, 2012.

[15] G. Bertino, A. M. Ardiri, P. M. Boemi et al., "A study about mechanisms of des-gamma-carboxy prothrombin's production in hepatocellular carcinoma," Panminerva Medica, vol. 50, no. 3, pp. 221-226, 2008.
[16] B. I. Carr, F. Kanke, M. Wise, and S. Satomura, "Clinical evaluation of lens culinaris agglutinin-reactive $\alpha$-fetoprotein and des$\gamma$-carboxy prothrombin in histologically proven hepatocellular carcinoma in the United States," Digestive Diseases and Sciences, vol. 52, no. 3, pp. 776-782, 2007.

[17] M. L. Volk, J. C. Hernandez, G. L. Su, A. S. Lok, and J. A. Marrero, "Risk factors for hepatocellular carcinoma may impair the performance of biomarkers: a comparison of AFP, DCP, and AFP-L3," Cancer Biomarkers, vol. 3, no. 2, pp. 79-87, 2007.

[18] L. Bolondi, S. Sofia, S. Siringo et al., "Surveillance programme of cirrhotic patients for early diagnosis and treatment of hepatocellular carcinoma: a cost effectiveness analysis," Gut, vol. 48, no. 2, pp. 251-259, 2001.

[19] D. Wu, S. Wu, J. Lu, Y. Zhou, L. Xu, and C. Guo, "Rifaximin versus nonabsorbable disaccharides for the treatment of hepatic encephalopathy: a meta-analysis," Gastroenterology Research and Practice, vol. 2013, Article ID 236963, 9 pages, 2013.

[20] Y. Zhang, J. Lu, W. Dai et al., "Combination therapy of ursodeoxycholic acid and corticosteroids for primary biliary cirrhosis with features of autoimmune hepatitis: a meta-analysis," Gastroenterology Research and Practice, vol. 2013, Article ID 490731, 9 pages, 2013.

[21] J. Bruix, M. Sherman, J. M. Llovet et al., "Clinical management of hepatocellular carcinoma, conclusions of the barcelona-2000 EASL conference," Journal of Hepatology, vol. 35, no. 3, pp. 421430, 2001.

[22] P. Whiting, A. W. S. Rutjes, J. B. Reitsma, P. M. M. Bossuyt, and J. Kleijnen, "The development of QUADAS: A tool for the quality assessment of studies of diagnostic accuracy included in systematic reviews," BMC Medical Research Methodology, vol. 3, article 1, 2003.

[23] Y. H. Baek, J. H. Lee, J. S. Jang et al., "Diagnostic role and correlation with staging systems of PIVKA-II compared with AFP," Hepatogastroenterology, vol. 56, no. 91-92, pp. 763-767, 2009.

[24] R. Cui, J. He, F. Zhang et al., "Diagnostic value of protein induced by vitamin $\mathrm{K}$ absence (PIVKAII) and hepatomaspecific band of serum gamma-glutamyl transferase (GGTII) as hepatocellular carcinoma markers complementary to $\alpha$ fetoprotein," British Journal of Cancer, vol. 88, no. 12, pp. 18781882, 2003.

[25] F. A. Durazo, L. M. Blatt, W. G. Corey et al., "Des- $\gamma$-carboxyprothrombin, $\alpha$-fetoprotein and AFP-L3 in patients with chronic hepatitis, cirrhosis and hepatocellular carcinoma," Journal of Gastroenterology and Hepatology, vol. 23, no. 10, pp. 1541-1548, 2008.

[26] R. Kuromatsu, M. Tanaka, Y. Shimauchi et al., "Usefulness of ED036 kit for measuring serum PIVKA-II levels in small hepatocellular carcinoma," Journal of Gastroenterology, vol. 32, no. 4, pp. 507-512, 1997.

[27] A. S. Lok, R. K. Sterling, J. E. Everhart et al., "Des- $\gamma$-carboxy prothrombin and $\alpha$-fetoprotein as biomarkers for the early detection of hepatocellular carcinoma," Gastroenterology, vol. 138, no. 2, pp. 493-502, 2010.

[28] J. A. Marrero, G. L. Su, W. Wei et al., "Des-gamma carboxyprothrombin can differentiate hepatocellular carcinoma from nonmalignant chronic liver disease in American patients," Hepatology, vol. 37, no. 5, pp. 1114-1121, 2003.

[29] J. A. Marrero, Z. Feng, Y. Wang et al., “ $\alpha$-fetoprotein, des- $\gamma$ carboxyprothrombin, and lectin-bound $\alpha$-fetoprotein in early hepatocellular carcinoma," Gastroenterology, vol. 137, no. 1, pp. 110-118, 2009. 
[30] H. Okuda, T. Nakanishi, K. Takatsu et al., "Measurement of serum levels of des-gamma-carboxy prothrombin in patients with hepatocellular carcinoma by a revised enzyme immunoassay kit with increased sensitivity," Cancer, vol. 85, no. 4, pp. 812818, 1999.

[31] T. Sassa, T. Kumada, S. Nakano, and T. Uematsu, "Clinical utility of simultaneous measurement of serum high-sensitivity desgamma-carboxy prothrombin and Lens culinaris agglutinin Areactive alpha-fetoprotein in patients with small hepatocellular carcinoma," European Journal of Gastroenterology and Hepatology, vol. 11, no. 12, pp. 1387-1392, 1999.

[32] C. S. Wang, C. L. Lin, H. C. Lee et al., "Usefulness of serum des- $\gamma$-carboxy prothrombin in detection of hepatocellular carcinoma," World Journal of Gastroenterology, vol. 11, no. 39, pp. 6115-6119, 2005.

[33] Y. J. Yoon, K. Han, and D. Y. Kim, "Role of serum prothrombin induced by vitamin $\mathrm{K}$ absence or antagonist-II in the early detection of hepatocellular carcinoma in patients with chronic hepatitis B virus infection," Scandinavian Journal of Gastroenterology, vol. 44, no. 7, pp. 861-866, 2009.

[34] K. Taketa, “ $\alpha$-fetoprotein: revaluation in hepatology," Hepatology, vol. 12, no. 6, pp. 1420-1432, 1990.

[35] A. M. Di Bisceglie and J. H. Hoofnagle, "Elevations in serum alpha-fetoprotein levels in patients with chronic hepatitis B," Cancer, vol. 64, no. 10, pp. 2117-2120, 1989.

[36] K. Hamamura, Y. Shiratori, S. Shiina et al., "Unique clinical characteristics of patients with hepatocellular carcinoma who present with high plasma des-gamma-carboxy prothrombin and low serum alpha-fetoprotein," Cancer, vol. 88, pp. 15571564, 2000.

[37] P. Cheng, W. Dai, F. Wang et al., "Ethyl pyruvate inhibits proliferation and induces apoptosis of hepatocellular carcinoma via regulation of the HMGB1-RAGE and AKT pathways," Biochemical and Biophysical Research Communications, vol. 443, no. 4, pp. 1162-1168, 2014.

[38] Y. Zhou, W. Dai, C. Lin et al., "Protective effects of necrostatin-1 against concanavalin a-induced acute hepatic injury in mice," Mediators of Inflammation, vol. 2013, Article ID 706156, 15 pages, 2013.

[39] M. Shen, J. Lu, W. Dai et al., "Ethyl pyruvate ameliorates hepatic ischemia-reperfusion injury by inhibiting intrinsic pathway of apoptosis and autophagy," Mediators of Inflammation, vol. 2013, Article ID 461536, 12 pages, 2013.

[40] F. Wang, W. Dai, Y. Wang et al., "The synergistic in vitro and in vivo antitumor effect of combination therapy with salinomycin and 5-fluorouracil against hepatocellular carcinoma," PLoS ONE, vol. 9, no. 5, Article ID e97414, 2014.

[41] S. Jia, J. Ren, P. Dong, and X. Meng, "Probing the hepatic progenitor cell in human hepatocellular carcinoma," Gastroenterology Research and Practice, vol. 2013, Article ID 145253, 5 pages, 2013. 


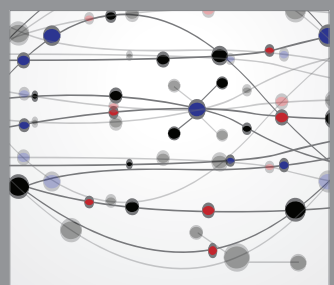

The Scientific World Journal
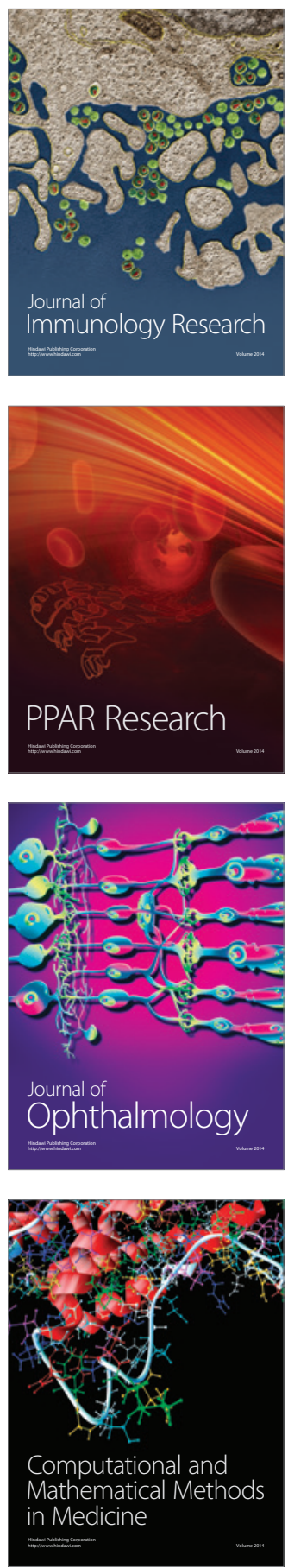

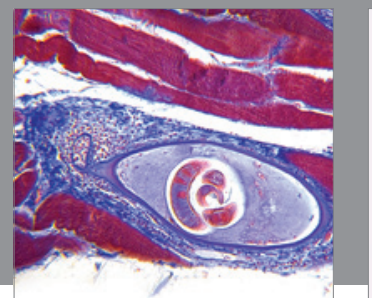

Gastroenterology

Research and Practice
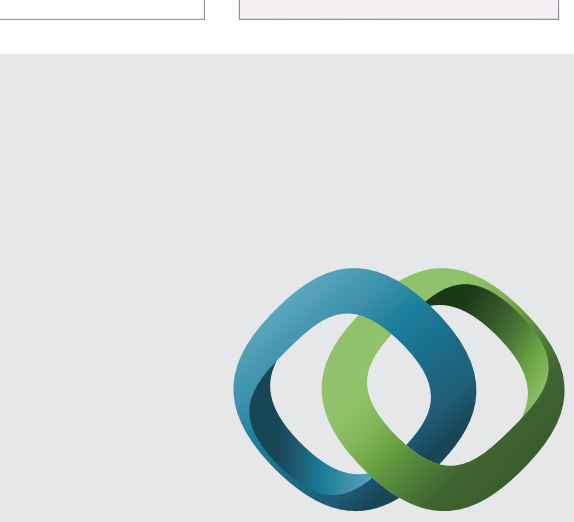

\section{Hindawi}

Submit your manuscripts at

http://www.hindawi.com
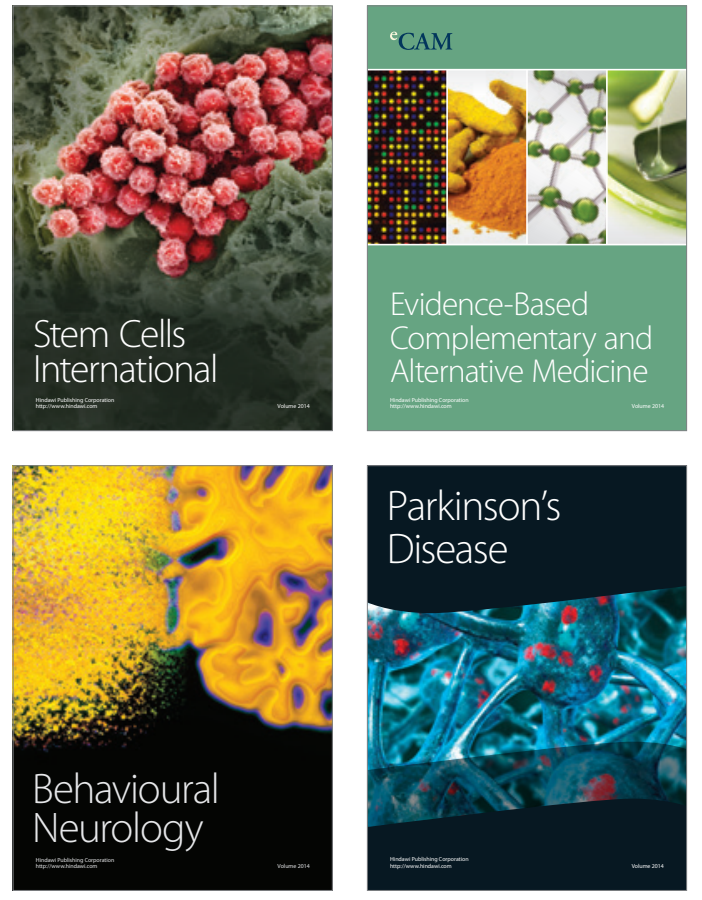
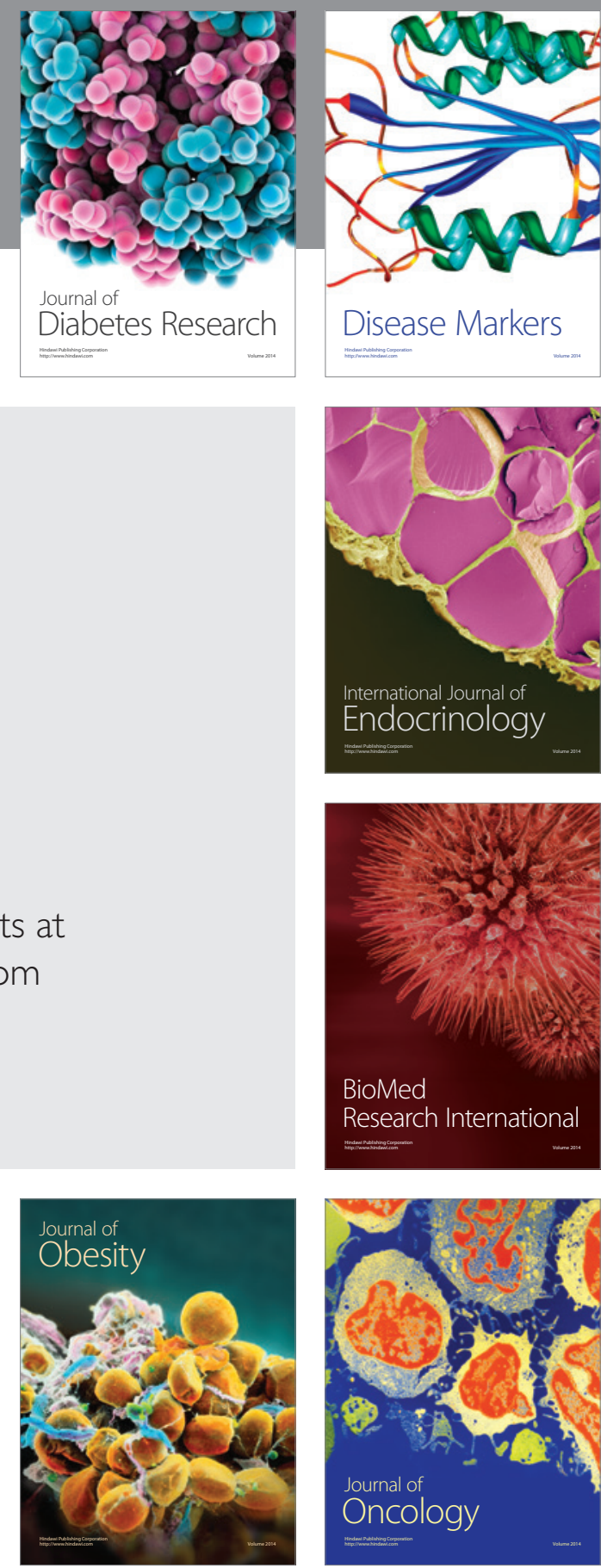

Disease Markers
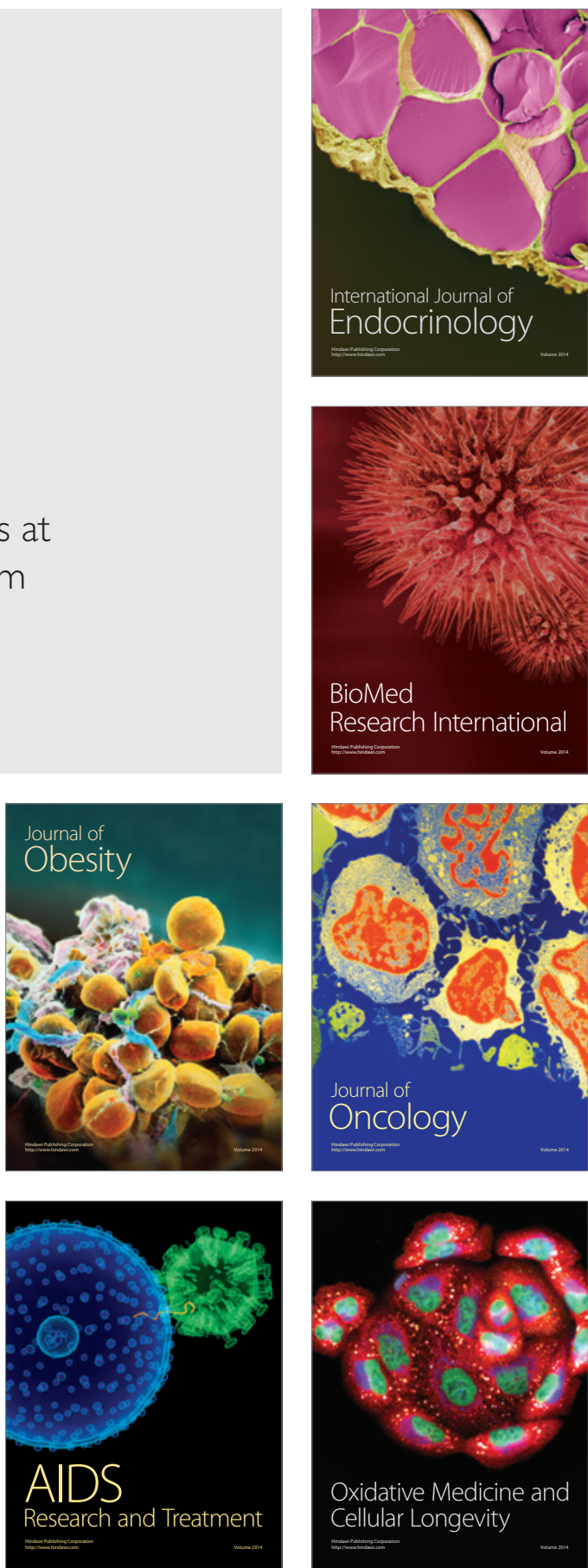